\title{
SYNTHESIS AND OPTIMIZATION OF GEMCITABINE-LOADED MIL-101NH2 (Fe) NANOCARRIERS: RESPONSE SURFACE METHODOLOGY APPROACH
}

\author{
PREETI KUSH ${ }^{1 *}$, JITENDER MADAN ${ }^{1}$, PARVEEN KUMAR ${ }^{2}$ \\ ${ }^{1}$ Department of Pharmaceutics, Chandigarh College of Pharmacy, Landran, I. K. Gujral Punjab Technical University, Jalandhar, Punjab, \\ India. ${ }^{2}$ Nanotechnology Divisions (H1), CSIR-CSIO, Chandigarh, India. Email: preetikush85@gmail.com
}

Received: 03 June 2019, Revised and Accepted: 27 June 2019

\section{ABSTRACT}

Objective: The objective of the present study is to synthesize and optimize gemcitabine (GEM)-loaded MIL-101 $\mathrm{NH}_{2}$ (Fe) nanocarriers. The design of experiments is used to optimize the formulation for higher encapsulation efficiency (EE) for effective drug delivery.

Materials and Methods: MIL-101 $\mathrm{NH}_{2}(\mathrm{Fe})$ was synthesized by microwave-assisted hydrothermal method. Central composite design (CCD) under response surface methodology was used for the optimization of GEM encapsulation into the MIL-101 $\mathrm{NH}_{2}(\mathrm{Fe})$. The most influential variable that affects the EE was investigated by Perturbation plot. Validation of the design was carried out by performing the experiments under optimal conditions. Further optimized formulation was physicochemically characterized for particle size, surface charge, and surface morphology using zetasizer and scanning electron microscopy (SEM), respectively. Structural integrity of the optimized formulation was carried out by Powder X ray crystallography (PXRD). Fourier-transform infrared (FTIR) spectroscopy was used for the confirmation of GEM loading. Accelerated storage stability analysis was also performed to find out the related parameters.

Results: Here in this work, crystalline MIL-101NH 2 (Fe) has been successfully synthesized by microwave radiation method. The optimization result revealed that process variables such as GEM concentration, $\mathrm{pH}$, and time significantly affect the desired constraint, EE. Perturbation plot evidenced that among all the variables, $\mathrm{pH}$ is the most significant factor followed by drug concentration and time. The optimized formulation exhibited $76.4 \pm$ $7 \%$ EE and average particle size of $252.9 \pm 9.23 \mathrm{~nm}$. PXRD and SEM results demonstrated that the optimized formulation was crystalline in nature. FTIR spectroscopy confirms the presence of drug inside the MIL-101 $\mathrm{NH}_{2}(\mathrm{Fe})$. In vitro release profile revealed that MIL-101NH $\mathrm{N}_{2}(\mathrm{Fe})-\mathrm{GEM}$ exhibited the sustained release up to $72 \mathrm{~h}$ in comparison to the native GEM. Storage-stability studies also indicate that MIL-101NH $\mathrm{N}_{2}(\mathrm{Fe})$-GEM has a shelf life of 6 months.

Conclusion: The EE of GEM in MIL- $101 \mathrm{NH}_{2}(\mathrm{Fe})$ can be altered by varying the drug concentration and $\mathrm{pH}$ during the impregnation.

Keywords: MIL-101 $\mathrm{NH}_{2}(\mathrm{Fe})$, Gemcitabine, Optimization, Central composite design, Response surface methodology, Encapsulation efficiency, Perturbation plot.

(c) 2019 The Authors. Published by Innovare Academic Sciences Pvt Ltd. This is an open access article under the CC BY license (http://creativecommons. org/licenses/by/4. 0/) DOI: http://dx.doi.org/10.22159/ajpcr.2019.v12i8.34430

\section{INTRODUCTION}

Drug gemcitabine (GEM) is one among the Food and Drug Administrative authority-approved drugs, which is mainly used for the first-line therapy for advanced and metastatic pancreatic cancer [1-3]. It is a difluoro analog of deoxycytidine which is transported to cells by nucleoside transporters, where it is phosphorylated to difluorodeoxycytidine diphosphate (dFdCDP, ribonucleotide reductase inhibitor) and triphosphate (dFdCTP, compete with cytidine phosphate). It is found that the deficiency of these transporters causes resistance to GEM therapy [4-6]. GEM is used for the treatment of various cancers such as nonsmall cell lung, bladder, pancreatic, breast, colon, cervical, ovarian, and hepatocellular cancer [7]. Unfortunately, GEM has short plasma half-life of 8-17 min in human and 9 min in murine [8-10] because of rapidly and extensively deamination by cytidine deaminase in the blood, liver, kidney, and other tissues $[11,12]$ to the inactive metabolite difluorodeoxyuridine (dfdU) which is excreted in the urine. However, the short half-life and low permeability are the major setback to the current clinical treatment with the drug. To achieve the therapeutic level of drug, frequent intravenous infusion is required at high dose which causes several side effects $[12,13]$. Thus, various attempts have been made to deliver GEM with the aim to improve pharmacokinetics and tumor delivery of this compound for more effective chemotherapy. GEM has been studied in different polymeric systems such as magnetic poly $\varepsilon$-caprolactone nanoparticles [14], micelles [15], and gold nanoparticles for pancreatic cancer treatment [16]. Several liposomal formulations have also been prepared and evaluated, e.g., pH-sensitive stearoylPEG-poly(methacryloyl sulfadimethoxine)-coated liposomes [17] and hyaluronic acid-coated liposomes for pancreatic adenocarcinoma cells [18]. Among these approaches, liposomes were the most effective carrier for delivery, but there are certain limitations faced by liposomes such as poor stability during storage [19]. Being a hydrophilic molecule, GEM is located in the aqueous compartment of liposomes and leads to diffusion of the drug during storage $[19,20]$. Therefore, encapsulation and drug release profile may change during the storage of formulation.

Nanocarriers reported in the literature have certain limitations such as low entrapment efficiency, burst release effect, and difficulty to engineer external surface for in vivo fate [21]. To circumvent these problems, a new class of highly tunable hybrid materials coordinated by metal and organic bridging ligand known as metal-organic frameworks (MOFs) has emerged as promising drug delivery system. These can be synthesized under mild conditions via coordinationdirected self-assembly process $[19,22]$. Their tunable pore sizes, shapes, large surface area to volume ratio $\left(3100-5900 \mathrm{~m}^{2} \mathrm{~g}^{-1}\right)$, intrinsic biodegradability [23], and tailored functionalities have provided a good choice in various applications such as gas storage, catalysis, and chemical sensing [24]. Similar features of MOFs have also attracted the pharmaceutical researcher for drug delivery applications [25]. Recently, MOFs have been investigated for loading and release of several drug molecules (e.g., azidothymidine (AZT), doxorubicin, cisplatin, 
5-fluorouracil, ibuprofen, topotecan, and busulfan) [26]. MOFs can be synthesized in nanoregimen by well-established techniques and methods in nanotechnology [27]. Materials of Institut Lavoisier (MIL) family is the first group of MOF discovered by Férey et al. for the delivery of ibuprofen with chromium-based MIL-101 [28]. MIL family is engineered by trivalent metal centers connected with carboxylic acid. It was found that drugs with polar complexing groups bind eventually to the coordinative unsaturated iron Lewis acid sites (CUS), leading to high encapsulation efficiencies (EEs), high payloads, and controlled release [29,30]. MIL$101 \mathrm{NH} 2(\mathrm{Fe})$ is the most stable iron (Fe)-based MOF , already been used for bioactive [31] and magnetic compounds [32]. MIL- $101 \mathrm{NH}_{2}(\mathrm{Fe})$ is a rigid zeotype Mobil thirty nine (MTN) crystal structure that possesses two types of windows, i.e., large hexagonal windows with a pore diameter of $34 \mathrm{~A}^{\circ}$ and small pentagonal window with a pore diameter of $29 \mathrm{~A}^{\circ}[21]$.

Here, this is the first report on the optimization of drug-loading methods by central composite design (CCD) along with response surface methodology (RSM), an ideal tool for process optimization. MIL-101 $\mathrm{NH}_{2}(\mathrm{Fe})$ was synthesized by microwave-assisted method and characterized by different instrumental techniques, such as scanning electron microscopy (SEM), Powder X-ray diffraction (PXRD), and Fourier-transform infrared (FTIR) spectroscopy. Further encapsulation of GEM was carried out by impregnation method. The effect of GEM concentration, $\mathrm{pH}$, and impregnation time on the EE was assessed CCD along with RSM $[33,34]$. The optimal condition for the achievement of higher EE was validated by performing the same experiments. The optimized formulation was further characterized for confirmation of drug loading and stability analysis.

\section{MATERIALS AND METHODS}

Materials

GEM was purchased from Sigma-Aldrich, India. Iron (III) chloride hexahydrate (Alfa Aesar, 98\%), amino-terephthalic acid, and absolute ethanol (Loba Chemie, Mumbai, 99\%) were used for MIL-101 $\mathrm{NH}_{2}$ synthesis and their activation. De-ionized water from Millipore Direct Q
3 (Bangalore, India) was used for all aqueous preparations, e.g., buffer and solutions.

\section{Synthesis of MIL-101 $\mathrm{NH}_{2}(\mathrm{Fe})$}

MIL-101 $\mathrm{NH}_{2}(\mathrm{Fe})$ was synthesized by microwave-assisted hydrothermal method with minor modification in the previous method [29,35,36]. Briefly, a mixture of iron chloride ( $9 \mathrm{mmol}$ ) and amino-terephthalic acid ( $5 \mathrm{mmol}$ ) was dissolved in $400 \mathrm{ml}$ of deionized water for $6 \mathrm{~min}$ at $170^{\circ} \mathrm{C}$ at 400 Watt (Mars-5, CEM, US). The synthesized MOF was collected by centrifugation for $10 \mathrm{~min}$ at $10,000 \mathrm{~g}$. Product was washed with $50 \mathrm{ml}$ of absolute ethanol to remove the residual ligand and collected by centrifugation. Encapsulation of GEM was performed by impregnation of the aqueous solution of drug in MOF. For encapsulation, $25 \mathrm{mg}$ of lyophilized MIL-101 $\mathrm{NH}_{2}(\mathrm{Fe})$ was suspended in $5 \mathrm{ml}$ of freshly prepared drug solutions $(1 \mathrm{mmol})$ at $80 \%$ of the maximum solubility in water. The suspensions were stirred for a maximum of $24 \mathrm{~h}$ at room temperature, and $100 \mu \mathrm{l}$ of the sample was collected at different time intervals at room temperature. These samples were further centrifuged and lyophilized [37].

\section{Experimental design}

CCD-RSM methodology was used to investigate systemic effect of three process variables on EE of GEM inside the MIL-101 $\mathrm{NH}_{2}(\mathrm{Fe})$. All the experiments were designed by Design-Expert software 10.0.8.0 trial version yielded 30 experiments (Table 1) for the synthesis of MIL- $101 \mathrm{NH}_{2}$ (Fe)-GEM. The variables were selected on the basis of preliminary experiments. Table 2 displays the range of selected variables.

The mathematical relationship between independent variables and their response can be modeled by polynomial model Equation 1 :

$Y=\beta 0+\sum_{i=1}^{3} \beta i X i+\sum_{i=1}^{3} \sum_{j=1}^{3} \beta i j X i X j+\sum_{i=1}^{3} \beta i i X i 2$

Where $Y$ is the measured response associated with each factor level combinations; $\beta_{0}$ is the Intercept; $\beta$ i (for $i=1,2$, and 3) are the linear

Table 1: Experimental design generated by central composite design using three independent variables along with experiment results

\begin{tabular}{|c|c|c|c|c|c|}
\hline Type & Run & GEM concentration $(\mathrm{mg} / \mathrm{ml})(\mathrm{A})$ & pH (B) & Time (min) (C) & EE (\%) \\
\hline Factorial & 1 & 300 & 3 & 30 & 52 \\
\hline Factorial & 2 & 100 & 3 & 30 & 40 \\
\hline Factorial & 3 & 300 & 6 & 1440 & 10 \\
\hline Factorial & 4 & 100 & 6 & 30 & 15 \\
\hline Axial & 5 & 0 & 4.5 & 735 & 0 \\
\hline Factorial & 6 & 100 & 3 & 30 & 41 \\
\hline Axial & 7 & 200 & 4.5 & 2145 & 79 \\
\hline Axial & 9 & 200 & 1.5 & 735 & 10 \\
\hline Factorial & 10 & 300 & 3 & 1440 & 51 \\
\hline Factorial & 11 & 100 & 3 & 1440 & 42 \\
\hline Factorial & 12 & 300 & 6 & 30 & 12 \\
\hline Factorial & 13 & 100 & 6 & 1440 & 15 \\
\hline Factorial & 14 & 100 & 6 & 1440 & 15 \\
\hline Axial & 15 & 200 & 4.5 & -675 & 55 \\
\hline Center & 16 & 200 & 4.5 & 735 & 79 \\
\hline Center & 18 & 200 & 4.5 & 735 & 79 \\
\hline Factorial & 19 & 300 & 3 & 1440 & 53 \\
\hline Center & 20 & 200 & 4.5 & 735 & 78 \\
\hline Factorial & 21 & 100 & 6 & 30 & 16 \\
\hline Factorial & 22 & 300 & 3 & 30 & 51 \\
\hline Center & 23 & 200 & 4.5 & 735 & 75 \\
\hline Factorial & 24 & 300 & 6 & 30 & 12 \\
\hline Axial & 25 & 400 & 4.5 & 735 & 72 \\
\hline Axial & 26 & 200 & 7.5 & 735 & 12 \\
\hline Factorial & 27 & 300 & 6 & 1440 & 20 \\
\hline Center & 28 & 200 & 4.5 & 735 & 80 \\
\hline Factorial & 29 & 100 & 3 & 1440 & 41 \\
\hline Center & 30 & 200 & 4.5 & 735 & 78 \\
\hline
\end{tabular}

GEM: Gemcitabine, EE: Encapsulation efficiency 
Table 2: Optimization of parameters

\begin{tabular}{llllll}
\hline Factors & Units & $\mathbf{- 1}$ & $\mathbf{+ 1}$ & $\mathbf{- \alpha}$ & $\mathbf{+ \alpha}$ \\
\hline Initial drug concentration & $\mu \mathrm{g} / \mathrm{ml}$ & 100 & 300 & 0 & 400 \\
$\mathrm{pH}$ & & 3 & 6 & 1.5 & 7.5 \\
Impregnation time & $\min$ & 30 & 1440 & -675 & 2145 \\
\hline
\end{tabular}

Experimental range and level of independent variables were selected for the synthesis of MIL-101 $\mathrm{NH}_{2}$ by CCD. -1 and +1 are coded value of independent variables represents low and high value, respectively. Alpha $(\alpha)$ in coded units was the axial distance from the center point and made the design rotatable. MIL: Materials of Institut Lavoisier, CCD: Central composite design

effects, the $\beta i i$ are the quadratic effects, the $\beta i j$ 's (for $i, j=1,2$, and 3, $i<j$ ) are the interaction between the $i^{\text {th }}$ and $j^{\text {th }}$ variables. $X i$ and $X j$ are the coded value for the processing variables.

\section{Characterization}

\section{Particle size, polydispersity index, and zeta potential}

Zetasizer (Malvern Nano-ZS, Zetasizer Nano series, UK) was used for the determination of particle size. All the measurements were carried out at $90^{\circ}$ angle. Each sample was diluted with Milli Q water. For zeta potential measurement, a $150 \mathrm{mV}$ electric field was applied and electrophoretic velocity of samples was measured. All the experiments were performed in triplicate $(n=3)$.

\section{Field emission scanning electron microscopy}

The structure and morphology of the particles were analyzed by field emission SEM (FESEM; 4300S, Hitachi). For SEM analysis, dried samples were mounted on metal stubs with the help of double-sided carbon tape. The samples were sputter coated with gold under vacuum and then examined.

\section{Powder X-ray crystallography}

Crystalline nature of MIL-101 $\mathrm{NH}_{2}(\mathrm{Fe})$ was investigated using powder X-ray diffractometer (D5000 Bruker diffractometer) $(\lambda \mathrm{Cu} \mathrm{K \alpha}, \mathrm{K} \alpha 2)$ from $0^{\circ}$ to $40^{\circ}(2 \theta)$ using a step size of $0.02^{\circ}$ and $4^{\circ}$ per step in continuous mode.

\section{Fourier-transform infrared spectroscopy}

FTIR spectra of samples were obtained using an FTIR spectrometer (Nicolet Continuum XL, Thermo Fisher Scientific). Briefly, the sample and potassium bromide were mixed well with a ratio of 1:10, followed by being compressed into a disk. Scans were carried out in wave number $400-4000 \mathrm{~cm}^{-1}$ at a resolution of $4 \mathrm{~cm}^{-1}$. Infrared spectroscopy in ATR mode (Alpha Bruker) using Opus software was performed to confirm the presence of the drug in the formulation.

\section{Encapsulation efficiency}

For the quantification of GEM loaded in MIL- $101 \mathrm{NH}_{2}(\mathrm{Fe}), 10 \mathrm{mg}$ of dried samples was treated with ultrasonic waves for $60 \mathrm{~min}$ using ethanol as extracting medium. The samples were centrifuged at $10,000 \mathrm{rpm}$ for $10 \mathrm{~min}$, and the supernatant was used to analyze nonadsorbed drug. The concentration of adsorbed and nonadsorbed drug was determined by ultraviolet (UV)-visible spectrophotometer at $268 \mathrm{~nm}$ based on the standard calibration curve of GEM in the range of $2-100 \mu \mathrm{g} / \mathrm{ml}$. Equations 2 and 3 were used to calculate encapsulated drug concentration and EE, respectively.

Encapsulated drug concentration $(\mu \mathrm{g})=$ Initial drug concentration $(\mu \mathrm{g})$ - non-encapsulated drug concentration $(\mu \mathrm{g})$

Encapsulation efficiency(\%)

$=\frac{\text { Adsorbed drug concentration }(\mu \mathrm{g})}{\text { Initial drug concentration }(\mu \mathrm{g})} \times 100$
In vitro drug release

For in vitro release, dialysis bag containing $2.5 \mathrm{mg}$ of MIL-101NH $\mathrm{N}_{2}(\mathrm{Fe})-$ GEM was suspended in each of the $10 \mathrm{ml}$ of phosphate buffer solution (PBS, $\mathrm{pH}=7.4$, $9.5 \mathrm{mM}$, Lonza). These suspensions were kept under rotary agitation up to $72 \mathrm{~h} .0 .5 \mathrm{ml}$ sample was taken from the release medium and replaced by fresh buffer to maintain the sink condition and centrifuged to obtain supernatant. Supernatant was used to study drug release in different media by high-performance liquid chromatography (HPLC) [22]. HPLC analysis was performed using a water pump (600E) connected to a C18 column (4.6 $\mathrm{mm} \times 250 \mathrm{~mm}$ ) (Agilent technology 1220 Infinity LC, Germany) coupled with a UV detector $(\lambda=268 \mathrm{~nm})$ and EZ Chrome Elite Software. The mobile phase consisted of a mixture of acetonitrile: $\mathrm{H}_{2} \mathrm{O}(10: 90), \mathrm{NH}_{4} \mathrm{H}_{2} \mathrm{PO}_{4}(50 \mathrm{mM})$, and TEAA $(5 \mathrm{mM})$. $50 \mu \mathrm{L}$ of the sample was injected at a flow rate of $1 \mathrm{ml} / \mathrm{min}$. Semiquantitative analysis was performed using standard calibration of different compounds in the range of $2-100 \mu \mathrm{g} / \mathrm{ml}$ [22]

\section{Storage stability analysis}

Stability analysis was carried out at $25 \pm 2^{\circ} \mathrm{C} / 60 \pm 5 \%$ relative humidity (RH). Freshly prepared freeze-dried samples of each formulation were sealed in vials and placed in a stability chamber at $25 \pm 2^{\circ} \mathrm{C} / 60 \pm 5 \%$ RH for 6 months. The samples were analyzed for color, aggregation, crystallinity, and particle size and entrapment efficiency with a sampling frequency of 1 month for 6 months. Experiments were performed in triplicate.

\section{Statistical analysis}

Design-Expert software was used for statistical analysis (Version 10.0.8.0), where analysis of relationship between the response variable "Y" and the entire set of "X" variables at $95 \%$ level of significance variance was significant, when $\mathrm{p}<0.05$. An F-test was used to determine the overall regression. Selection of best fitting model was based on comparative study of different statistical parameters: coefficient of variation, correlation coefficients $\left(\mathrm{R}^{2}\right)$, adjusted correlation (adjusted $\mathrm{R}^{2}$ ) coefficient.

\section{RESULTS AND DISCUSSION}

\section{Optimized synthesis of MIL-101 $\mathrm{NH}_{2}$ (Fe)-GEM by CCD}

CCD methodology is the best method for optimization of the formulation using minimum number of experiments. Table 1 presents the experimental results using the three independent variables on EE.

The EE value ranged from 0 to $80 \%$. Response surface quadratic model was suggested by quadratic polynomial analysis for giving the relationship between process variables and their responses in terms of coded values in Equation 4.

Encapsulation efficiency $=74.76+7.50 A-10.50 B+2.33 C-3.12 A B+$ $0.3750 A C+0.125 B C-13.05 A^{2}-19.30 B^{2}-5.30 C^{2}(4)$

where $\mathrm{A}, \mathrm{B}$, and $\mathrm{C}$ are GEM concentration, $\mathrm{pH}$, and time, respectively. Synergistic and antagonistic effects were presented by + and - symbol, respectively [38]. Analysis of variance (ANOVA) was used to find out the effect of processing variables, interaction between the variables, and statistical significance. F value, $P$ value, and sum of squares (SS) are the important parameters for the interpretation of ANOVA table. Higher $F$ and SS value the imply significance of model and vice versa. $p$ value parameter is contrary to $\mathrm{F}$ value parameter. Small probability $\mathrm{p}<0.05$ indicates the significance of model and used to predict the response function precisely. Small probability value $(\mathrm{p}<0.0001)$ revealed that the selected quadratic model was highly significant and could be used for accurate prediction of responses as shown in Table 3. Goodness of fit was supported by large value of $\mathrm{R}^{2}$ and adjusted $\mathrm{R}^{2}$.

Table 3 reveals that $\mathrm{A}, \mathrm{B}, \mathrm{A}^{2}$, and $\mathrm{B}^{2}$ were the significant factors $(p<0.05)$ and $C$ and $C^{2}$ were non-significant variables $(p>0.05)$. The above statistical results revealed that CCD was adequate to optimize the GEM encapsulation within the range of determined variables. The 
Table 3: Analysis of variance results for encapsulation efficiency of Materials of Institut Lavoisier-101 $\mathrm{NH}_{2}$ (Fe)-gemcitabine using quadratic model

\begin{tabular}{|c|c|c|c|c|c|c|}
\hline Source & Sum of squares & df & Mean square & $\boldsymbol{F}$ & $\mathbf{p}$ & Remarks \\
\hline Model & $18,023.61$ & 9 & 2002.62 & 8.16 & $<0.0001$ & Significant \\
\hline A-GEM concentration & 1350.00 & 1 & 1350.00 & 5.50 & $<0.0294$ & Significant \\
\hline B-pH & 2646.00 & 1 & 2646.00 & 10.78 & $<0.0037$ & Significant \\
\hline C-time & 130.67 & 1 & 130.67 & 0.5323 & 0.4741 & \\
\hline $\mathrm{AB}$ & 156.25 & 1 & 156.25 & 0.6365 & 0.4343 & \\
\hline $\mathrm{AC}$ & 2.25 & 1 & 2.25 & 0.0092 & 0.9247 & \\
\hline $\mathrm{BC}$ & 0.2500 & 1 & 0.2500 & 0.0010 & 0.9749 & \\
\hline $\mathrm{B}^{2}$ & $10,433.58$ & 1 & $10,433.58$ & 42.50 & $<0.0001$ & Significant \\
\hline $\mathrm{C}^{2}$ & 787.58 & 1 & 787.58 & 3.21 & 0.0884 & \\
\hline Residual & 4909.36 & 20 & 245.47 & & & \\
\hline Lack of fit & 4840.48 & 5 & 968.10 & 210.84 & $<0.0001$ & Significant \\
\hline Pure error & 68.87 & 15 & 4.59 & & & \\
\hline Cor total & $22,932.97$ & 29 & & & & \\
\hline
\end{tabular}

df: Degree of freedom, p: Probability, $R^{2}: 0.8566$, Predicted R²: 0.7406, Adjusted R²: 0.8298, GEM: Gemcitabine

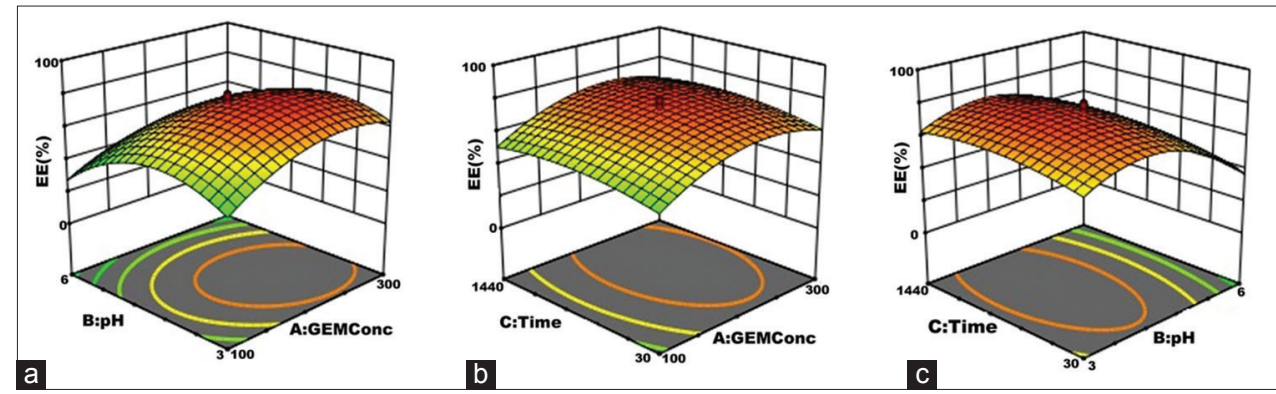

Fig. 1: The three-dimensional graphs present effect of process variables on encapsulation efficiency of $\mathrm{MIL}^{101 \mathrm{NH}_{2}}(\mathrm{Fe})$-gemcitabine computed by central composite design and response surface methodology. (a) pH versus gemcitabine concentration, time was kept constant; (b) time versus gemcitabine concentration, $\mathrm{pH}$ value was kept constant; (c) time versus pH, gemcitabine concentration was kept constant

model regression coefficient $\left(R^{2}\right)$ is in reasonable agreement with the predicted and adjusted $\mathrm{R}^{2}$ values.

\section{Effect of process parameters and their interaction}

After analyzing the most significant variables which affect the main constraint (EE), RSM methodology was used for optimization. Fig. 1 presents the three-dimensional (3D) response plots of EE versus significant variables.

Design-Expert software was used to plot the response in 3D form to show the interaction of three independent variables and dependent variable. Fig. 1 shows that $\mathrm{pH}$ and drug concentration significantly affect the EE. Equation 4 revealed that GEM showed positive effect on EE while $\mathrm{pH}$ showed its negative effect also supported by Fig. 1. At lower $\mathrm{pH}$, EE was less; however, when $\mathrm{pH}$ was increased up to 4.5, then, there was a significant increase in EE; however, at higher $\mathrm{pH}$, i.e., 6 , the EE was reduced (Fig. 1a). On the other hand, similar trends were also shown by increasing drug concentration regardless of the $\mathrm{pH}$. As per the literature, $\mathrm{pH}$ is an important process parameter which affects the encapsulation of drug, and it also influences the surface charge and chemical structure of the molecules $[39,40]$. At lower pH, GEM and MIL$101 \mathrm{NH}_{2}(\mathrm{Fe})$ possess positive charge which leads to less encapsulation of GEM [41]. When $\mathrm{pH}$ was changed by $\mathrm{NaOH}$, MOF becomes negative by giving the proton to the solvent [42]. The optimum $\mathrm{pH}$ for higher EE was found 4.5. At higher $\mathrm{pH}$, MOF became more negative and GEM was neutral at 6-7 $\mathrm{pH}$ [43]. Hence, there is less interaction between GEM and MOF. Fig. 1b presents that when drug concentration was increased, EE was also increased to a certain extent; however, at higher concentration, there was no impact of drug concentration. At low drug concentration, enough site was available for encapsulation; however, when concentration was increased, all sites became saturated and no impact of increased drug concentration [40]. Fig. 1c demonstrates that time has not significant $(p>0.05)$ on EE. In Design-Expert, there

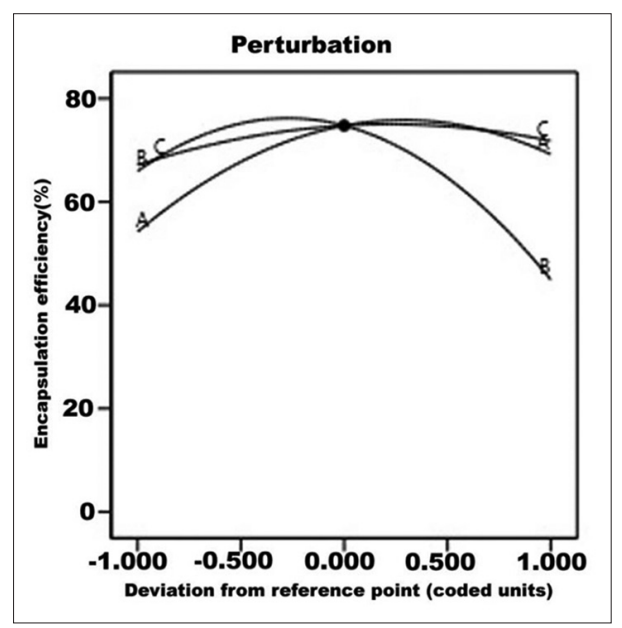

Fig. 2: Perturbation plot presents the effect of individual variable on encapsulation efficiency where $A, B$, and $C$ are gemcitabine concentration, $\mathrm{pH}$, and time, respectively

are three ways for optimization: graphical optimization, numerical optimization, and point prediction [44]. In this study, we have selected numerical optimization, in which we have selected the best target for each factor, i.e., higher EE. To confirm the model adequacy for predicting the response function, we again performed the experiment using optimal condition given in Table 4 . Table 4 presents that the experimental results and predicted results are very close, suggesting the reliability of optimized formulation.

Fig. 2 presents the perturbation plots, used for better understanding the optimization procedure. The steepest curve presents the response 
Table 4: Comparison of predictive and experimental results optimal values for encapsulation efficiency of Materials of Institut Lavoisier-101 $\mathrm{NH}_{2}$ (Fe)-gemcitabine

\begin{tabular}{llll}
\hline Parameter & Optimum value & EE (\%) & Experimental value \\
\cline { 3 - 4 } & & Predictive value & $76.4 \pm 7$ \\
\hline Initial drug concentration $(\mathrm{mg} / \mathrm{ml})$ & 232.56 & 77.81 & \\
$\mathrm{pH}$ & 4.5 & & \\
Impregnation time $(\mathrm{min})$ & 895.65 & & \\
\hline
\end{tabular}

CCD provided data was used for performing experiments and observed that the predictive values are in accordance with experimental values. This approach can help in saving time for optimization of such formulations at production. Experimental values are presented in mean $\pm S D(n=3)$. Experimental values are presented in mean \pm SD (n=3). SD: Standard deviation, CCD: Central composite design, EE: Encapsulation efficiency
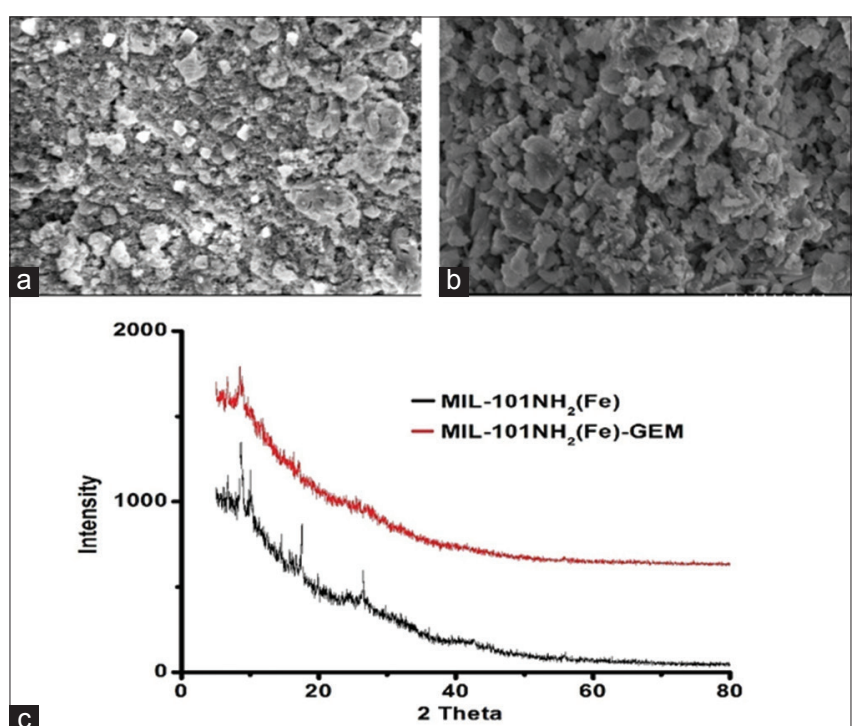

Fig. 3: Morphological characterization of metal-organic framework images of (a) scanning electron microscopy of MIL101NH2 (Fe); (b) SEM of MIL-101NH2 (Fe)-gemcitabine; (c) PXRD pattern of blank and drug loaded MIL-101NH2 (Fe)

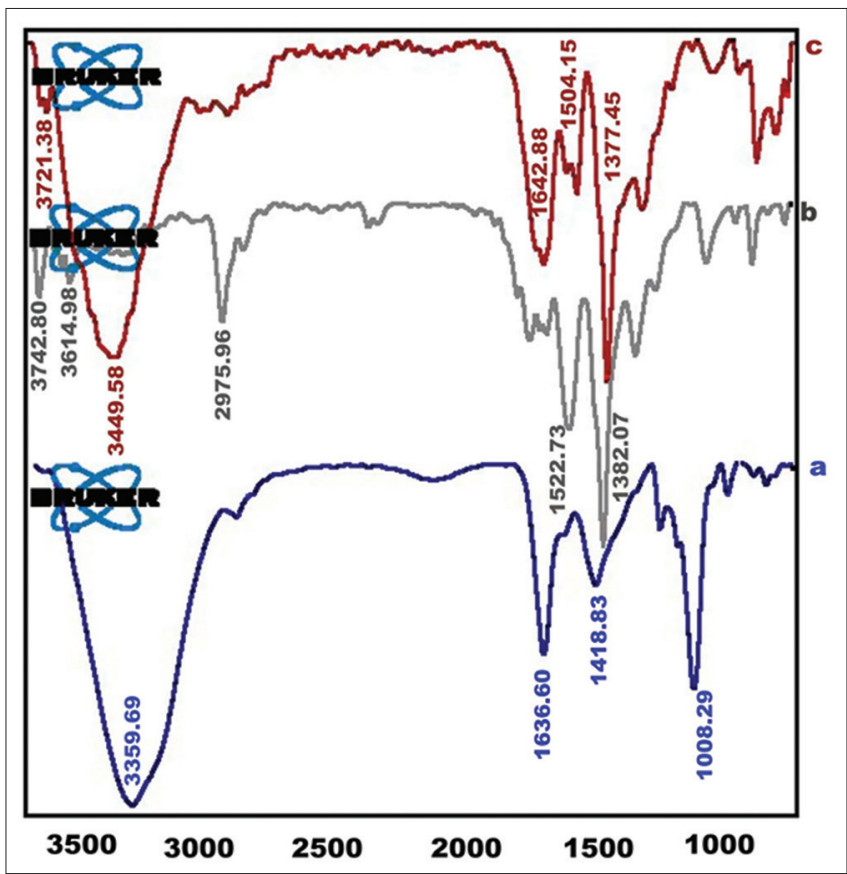

Fig. 4: Fourier transform infrared spectroscopy spectra of (a) gemcitabine; (b) MIL-101NH2 (Fe); (c) MIL-101NH2(Fe)gemcitabine in the region of $4000-500 \mathrm{~cm}-1$ sensitiveness to specific variable. Fig. 2 reveals that variable $\mathrm{B}(\mathrm{pH})$ is more influential on EE followed by A and C.

\section{Physicochemical characterization of optimized formulation}

Particle size analysis by dynamic light scattering (DLS) of freeze-dried MIL-101NH $\mathrm{N}_{2}(\mathrm{Fe})$ revealed an average particle diameter of $158.1 \pm$ $10 \mathrm{~nm}$. However, there was a slight increase in particle size of MIL$101 \mathrm{NH}_{2}$ (Fe)-GEM, i.e., $252.9 \pm 9.23 \mathrm{~nm}$. The increase in particle size was attributed to the encapsulation of drug into the MIL-101 $\mathrm{NH}_{2}(\mathrm{Fe})$. Zeta potential of MIL-101 $\mathrm{NH}_{2}(\mathrm{Fe})$ and MIL-101NH $\mathrm{N}_{2}$ (Fe)-GEM was determined according to the Helmholtz-Smoluchowski equation from their electrophoresis mobility and was found to be $30.75 \pm 3.8 \mathrm{mV}$ which shows good stability. MIL-101 $\mathrm{NH}_{2}(\mathrm{Fe})$ has shown a facetted-type architecture as observed by FESEM (Fig. 3a and b) and mean diameters of $158.1 \pm 10 \mathrm{~nm}$ correlated with DLS. SEM of MIL-101NH 2 (Fe) and MIL-101 $\mathrm{NH}_{2}(\mathrm{Fe})$-GEM was well crystalline structures. This was further confirmed by PXRD data in Fig. 3c which shows crystalline nature of MOF, good agreement with the literature [45]. No peak shift was observed in GEM-loaded MOF (MIL-101 $\mathrm{NH}_{2}$ [Fe]-GEM) which confirms that drug was comfortably accommodated in this porous MOF. GEMloaded MOF showed partial amorphization demonstrated by PXRD patterns (Fig. 3c).

\section{Fourier-transform infrared spectroscopy}

FTIR spectroscopy was performed for the confirmation of drug in these nanocarriers. The FTIR spectra (Fig. 4a) of GEM showed characteristics bending vibrations of amines at $1418 \mathrm{~cm}^{-1}$ and $1636 \mathrm{~cm}^{-1}$ and stretching vibration of amine at $3359 \mathrm{~cm}^{-1}$. Fig. $4 \mathrm{~b}$ shows the characteristic peak of MIL- $101 \mathrm{NH}_{2}(\mathrm{Fe})$ at $1382,1522,3614$, and $3742 \mathrm{~cm}^{-1}$, corresponding to $\mathrm{C}-\mathrm{N}$ stretch $\mathrm{C}-\mathrm{O}$ stretching and $\mathrm{N}-\mathrm{H}$ vibration (asymmetric and symmetric), respectively $[45,46]$. Drug-loaded MOF showed the presence of $\mathrm{N}-\mathrm{H}$ bands around $1642 \mathrm{~cm}^{-1}$, corresponding to the $\mathrm{N}-\mathrm{H}$ groups from the amine moieties and shift of band $3359 \mathrm{~cm}^{-1}$ to 3349 $\mathrm{cm}-1$, showing the presence of GEM NH2 groups (Fig. 4c)

\section{In vitro drug release of optimized formulation}

Fig. 5 presents the in vitro drug release profile of optimized formulation. GEM-loaded optimized formulation was found quite stable during the study time, i.e., $72 \mathrm{~h}$. GEM release profile from MIL- $101 \mathrm{NH}_{2}$ (Fe)-GEM was also significant (one-way ANOVA, $\mathrm{p}<0.05$ ) in comparison to native GEM. MIL-101 $\mathrm{NH}_{2}$ (Fe)-GEM showed burst effect up to $2 \mathrm{~h}$ of the study; however, later on, up to $72 \mathrm{~h}$ sustained release was observed. The reason of burst effect might be loosely attached molecule which was present on the surface of MOF. On the contrary, GEM was progressively released under physiological simulated conditions (PBS, $37^{\circ} \mathrm{C}$ ) with 25 , 60 , and $99.9 \%$ of drug release after $0.5,2$, and $6 \mathrm{~h}$, respectively. Thus, MIL-101NH $\mathrm{N}_{2}$ (Fe)-GEM nanoparticles clearly appeared as promising candidates for the delivery of GEM, showing both very high payloads and progressive drug release in physiological-simulated conditions.

\section{Storage stability analysis}

Stability studies were carried out at $25 \pm 2^{\circ} \mathrm{C} / 60 \pm 5 \%$ RH to find out the effect of storage temperature. The results of stability testing in Table 5 revealed no significant change in color, aggregation, and crystallinity, but there was a slight change in size and EE. Therefore, optimized formulation was found to be stable for 6 months. 
Table 5: Stability study of optimized formulation

\begin{tabular}{lllll}
\hline Parameter & 0 month & 1 month & 2 months & 4 months \\
\hline Colour change & - & - & - & - \\
Aggregation & - & - & - & - \\
Crystallinity & - & - & - & - \\
Particle size $(\mathrm{nm})^{*}$ & $252.9 \pm 9$ & $251 \pm 8$ & $251.8 \pm 7$ & - \\
EE $(\%)$ & $76.4 \pm 0.5$ & $75.6 \pm 1$ & $75.1 \pm 1.5$ & $253 \pm 10$ \\
\hline
\end{tabular}

*Mean \pm SD (n=3). SD: Standard deviation, -: No change, +: Small change, ++: Enough change, EE: Encapsulation efficiency

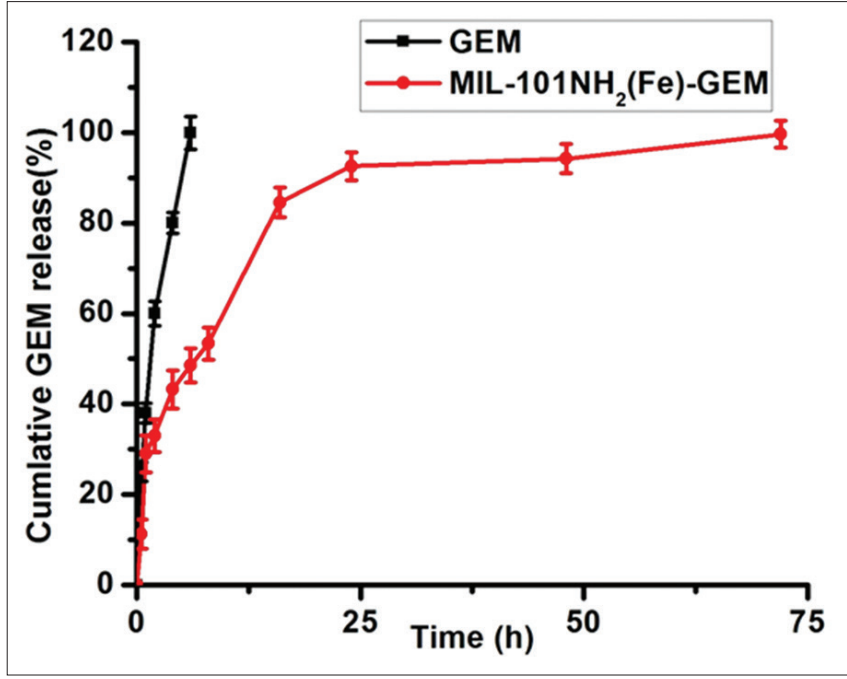

Fig. 5: Comparative cumulative $\%$ in vitro release profile of gemcitabine form $\mathrm{MIL-101 \textrm {NH } _ { 2 }}$ (Fe)-gemcitabine and native gemcitabine in phosphate buffer solution (pH 7.4)

\section{CONCLUSION}

MIL-101NH 2 (Fe) was successfully synthesized by microwave-assisted hydrothermal method. MIL-101 $\mathrm{NH}_{2}$ (Fe)-GEM was optimized by CCDRSM using quadratic polynomial model. Under optimum conditions, the experiments were again performed to check the validity of the design. The optimized formulation gave $76.4 \% \mathrm{EE}$ and average particle size of $252.9 \mathrm{~nm}$. The optimized formulation was physicochemically characterized by SEM and PXRD. Confirmation of drug loading was carried out by FTIR spectroscopy. The drug release profile of optimized formulation showed biphasic release pattern with initial burst release and later on sustained release. Storage-stability studies also indicate that MIL-100NH $\mathrm{N}_{2}$ (Fe)-GEM has a shelf life of 6 months. Further, the surface functionalities such as $-\mathrm{COOH}$ and $\mathrm{NH}_{2}$ groups can be utilized for binding of specific antibody or ligand for targeted drug delivery purpose.

\section{CONFLICTS OF INTEREST}

The authors have no conflicts of interest to declare.

\section{ACKNOWLEDGMENT}

The authors are thankful to I. K. Gujral Punjab Technical University, Punjab, India, for supporting the research. Parveen Kumar acknowledges the Department of Science and Technology-New Delhi for INSPIRE Faculty award.

\section{AUTHORS CONTRIBUTION}

Preeti Kush conceived the idea and all scientific discussions were done in group. Preeti Kush performed all the experiments and maximum characterization was done by Dr. Parveen Kumar. Dr. Jitender Madan contributed in refining and proof-reading the manuscript.

\section{REFERENCES}

1. Hertel LW, Boder GB, Kroin JS, Rinzel SM, Poore GA, Todd GC, et al. Evaluation of the antitumor activity of gemcitabine (2',2'-difluoro-2'deoxycytidine). Cancer Res 1990;50:4417-22.

2. Plunkett W, Huang P, Gandhi V. Preclinical characteristics of gemcitabine. Anticancer Drugs 1995;6 Suppl 6:7-13.

3. Burris HA $3^{\text {rd }}$, Moore MJ, Andersen J, Green MR, Rothenberg ML, Modiano MR, et al. Improvements in survival and clinical benefit with gemcitabine as first-line therapy for patients with advanced pancreas cancer: A randomized trial. J Clin Oncol 1997;15:2403-13.

4. Mackey JR, Mani RS, Selner M, Mowles D, Young JD, Belt JA, et al. Functional nucleoside transporters are required for gemcitabine influx and manifestation of toxicity in cancer cell lines. Cancer Res 1998:58:4349-57.

5. Pastor-Anglada M, Molina-Arcas M, Casado FJ, Bellosillo B, Colomer D, Gil J, et al. Nucleoside transporters in chronic lymphocytic leukaemia. Leukemia 2004;18:385-93.

6. Gourdeau H, Clarke ML, Ouellet F, Mowles D, Selner M, Richard A, et al. Mechanisms of uptake and resistance to troxacitabine, a novel deoxycytidine nucleoside analogue, in human leukemic and solid tumor cell lines. Cancer Res 2001;61:7217-24.

7. Razzazan A, Atyabi F, Kazemi B, Dinarvand R. In vivo drug delivery of gemcitabine with PEGylated single-walled carbon nanotubes. Mater Sci Eng C Mater Biol Appl 2016;62:614-25.

8. Abbruzzese JL, Grunewald R, Weeks EA, Gravel D, Adams T, Nowak B, et al. A phase I clinical, plasma, and cellular pharmacology study of gemcitabine. J Clin Oncol 1991;9:491-8.

9. Reid JM, Qu W, Safgren SL, Ames MM, Krailo MD, Seibel NL, et al. Phase I trial and pharmacokinetics of gemcitabine in children with advanced solid tumors. J Clin Oncol 2004;22:2445-51.

10. Moog R, Burger AM, Brandl M, Schüler J, Schubert R, Unger C, et al. Change in pharmacokinetic and pharmacodynamic behavior of gemcitabine in human tumor xenografts upon entrapment in vesicular phospholipid gels. Cancer Chemother Pharmacol 2002;49:356-66.

11. Immordino ML, Brusa P, Rocco F, Arpicco S, Ceruti M, Cattel L, et al. Preparation, characterization, cytotoxicity and pharmacokinetics of liposomes containing lipophilic gemcitabine prodrugs. J Control Release 2004;100:331-46.

12. Derakhshandeh K, Fathi S. Role of chitosan nanoparticles in the oral absorption of gemcitabine. Int J Pharm 2012;437:172-7.

13. Taranjit K, Sukhjinder K, Parminderjit K. Development and validation of UV-spectrophotometric methods for determination of gemcitabine hydrochloride in bulk and polymeric nanoparticles. Int J Appl Pharm 2017;9:60-5

14. Yang J, Lee H, Hyung W, Park SB, Haam S. Magnetic PECA nanoparticles as drug carriers for targeted delivery: Synthesis and release characteristics. J Microencapsul 2006;23:203-12.

15. Wang J, Zhang X, Cen Y, Lin X, Wu Q. Antitumor gemcitabine conjugated micelles from amphiphilic comb-like random copolymers. Colloids Surf B Biointerfaces 2016;146:707-15.

16. Patra CR, Bhattacharya R, Wang E, Katarya A, Lau JS, Dutta S, et al. Targeted delivery of gemcitabine to pancreatic adenocarcinoma using cetuximab as a targeting agent. Cancer Res 2008;68:1970-8.

17. Bersani S, Vila-Caballer M, Brazzale C, Barattin M, Salmaso S. PHsensitive stearoyl-PEG-poly(methacryloyl sulfadimethoxine) decorated liposomes for the delivery of gemcitabine to cancer cells. Eur J Pharm Biopharm 2014;88:670-82

18. Arpicco S, Lerda C, Dalla Pozza E, Costanzo C, Tsapis N, Stella B, et al. Hyaluronic acid-coated liposomes for active targeting of gemcitabine. Eur J Pharm Biopharm 2013;85:373-80.

19. Brusa P, Immordino ML, Rocco F, Cattel L. Antitumor activity and pharmacokinetics of liposomes containing lipophilic gemcitabine prodrugs. Anticancer Res 2007;27:195-9.

20. Cattel L, Ceruti M, Dosio F. From conventional to stealth liposomes: 
A new frontier in cancer chemotherapy. Tumori 2003;89:237-49.

21. Horcajada P, Chalati T, Serre C, Gillet B, Sebrie C, Baati T, et al. Porous metal-organic-framework nanoscale carriers as a potential platform for drug delivery and imaging. Nat Mater 2010;9:172-8.

22. Agostoni V, Chalati T, Horcajada P, Willaime H, Anand R, Semiramoth $\mathrm{N}$, et al. Towards an improved anti-HIV activity of NRTI via metal-organic frameworks nanoparticles. Adv Healthc Mater 2013;2:1630-7.

23. Huxford RC, Della Rocca J, Lin W. Metal-organic frameworks as potential drug carriers. Curr Opin Chem Biol 2010;14:262-8.

24. Horcajada P, Serre C, Vallet-Regí M, Sebban M, Taulelle F, Férey G, et al. Metal-organic frameworks as efficient materials for drug delivery. Angew Chem Int Ed Engl 2006;45:5974-8.

25. Kush P, Madan J, Kumar P. Application of central composite design and response surface methodology for optimization of metal organic framework: Novel carrier for drug delivery. Asian J Pharm Clin Res. Available from: https://www.innovareacademics.in/journals/index.php/ ajpcr/issue/archive its my first paper i.e 34299) 2019;12:34299.

26. He C, Liu D, Lin W. Nanomedicine applications of hybrid nanomaterials built from metal-ligand coordination bonds: Nanoscale metal-organic frameworks and nanoscale coordination polymers. Chem Rev 2015;115:11079-108.

27. Dey C, Kundu T, Biswal BP, Mallick A, Banerjee R. Crystalline metalorganic frameworks (MOFs): Synthesis, structure and function. Acta Crystallogr B Struct Sci Cryst Eng Mater 2014;70:3-10.

28. Férey G, Mellot-Draznieks C, Serre C, Millange F, Dutour J, Surblé S, et al. A chromium terephthalate-based solid with unusually large pore volumes and surface area. Science 2005;309:2040-2.

29. Agostoni V, Horcajada P, Noiray M, Malanga M, Aykaç A, Jicsinszky L, et al. A "green" strategy to construct non-covalent, stable and bioactive coatings on porous MOF nanoparticles. Nature 2015;5:7925-32.

30. di Nunzio MR, Agostoni V, Cohen B, Gref R, Douhal A. A "ship in a bottle" strategy to load a hydrophilic anticancer drug in porous metal organic framework nanoparticles: Efficient encapsulation, matrix stabilization, and photodelivery. J Med Chem 2014;57:411-20.

31. Horcajada P, Gref R, Baati T, Allan PK, Maurin G, Couvreur P, et al. Metalorganic frameworks in biomedicine. Chem Rev 2012;112:1232-68.

32. Ke F, Yuan YP, Qiu LG, Shen YH, Xie AJ, Zhu JF, et al. Facile fabrication of magnetic metal-organic framework nanocomposites for potential targeted drug delivery.J Mater Chem 2011;21:3843-8.

33. Amir AS, Praveen DC, Sagar SH. A design of experiment approach for optimization and characterization of etodolac ternary system using spray drying. Int J Pharm Pharm Sci 2017;9:223-40.

34. Shekar P, Kumar KS, Jabasingh SA, Radhakrishnan M, Balagurunathan R. Optimization of medium components for antibacterial metabolite production from marine streptomyces SP. PUA2 using response surface methodology. Int J Pharm Pharm Sci
2014;6:475-80.

35. Khan NA, Kang IJ, Seok HY, Jhung SH. Facile synthesis of nano-sized metal-organic frameworks, chromium-benzenedicarboxylate, MIL101. Chem Eng J 2011;166:1152-7.

36. Agostoni V, Anand R, Monti S, Hall S, Maurin G, Horcajada P, et al. Impact of phosphorylation on the encapsulation of nucleoside analogues within porous iron(iii) metal-organic framework MIL100(Fe) nanoparticles. J Mater Chem B 2013;1:4231-42.

37. Chalati T, Horcajada P, Couvreur P, Serre C, Ben Yahia M, Maurin G, et al. Porous metal organic framework nanoparticles to address the challenges related to busulfan encapsulation. Nanomedicine (Lond) 2011;6:1683-95.

38. Myers RH, Montgomery DC, Vining GG, Borror CM, Kowalski SM. Response surface methodology: A retrospective and literature survey. J Qual Technol 2004;36:53-77.

39. Naeimi S, Faghihian H. Application of novel metal organic framework, MIL-53(Fe) and its magnetic hybrid: For removal of pharmaceutical pollutant, doxycycline from aqueous solutions. Environ Toxicol Pharmacol 2017;53:121-32.

40. Massoudinejad M, Ghaderpoori M, Shahsavani A, Amini MM. Adsorption of fluoride over a metal organic framework Uio-66 functionalized with amine groups and optimization with response surface methodology. J Mol Liq 2016;221:279-86.

41. Hamarat Sanlıer S, Yasa M, Cihnioglu AO, Abdulhayoglu M, Yılmaz H, Ak G, et al. Development of gemcitabine-adsorbed magnetic gelatin nanoparticles for targeted drug delivery in lung cancer. Artif Cells Nanomed Biotechnol 2016;44:943-9.

42. Chau VT, Minhthanh HT, Du PD, Toan TT, Tuyen TN, Mau TX, et al. Metal-organic framework-101 (MIL-101): Synthesis, kinetics, thermodynamics, and equilibrium isotherms of remazol deep black RGB adsorption. J Chem 2018:2018:1-14.

43. Bornmann C, Graeser R, Esser N, Ziroli V, Jantscheff P, Keck T, et al. A new liposomal formulation of gemcitabine is active in an orthotopic mouse model of pancreatic cancer accessible to bioluminescence imaging. Cancer Chemother Pharmacol 2008;61:395-405.

44. Sumithra S, Shanmugasundaram P, Ravichandiran V. Quality by design-based optimization and validation of new reverse phasehigh-performance liquid chromatography method for simultaneous estimation of levofloxacin hemihydrate and ambroxol hydrochloride in bulk and its pharmaceutical dosage form. Asian J Pharm Clin Res 2016;9:190-6.

45. Wyszogrodzka G, Dorożyński P, Gil B, Roth WJ, Strzempek M, Marszałek B, et al. Iron-based metal-organic frameworks as a theranostic carrier for local tuberculosis therapy. Pharm Res 2018;35:144.

46. Wu B, Lin X, Ge L, Wu L, Xu T. A novel route for preparing highly proton conductive membrane materials with metal-organic frameworks. Chem Commun (Camb) 2013;49:143-5. 